\title{
LA-UR-18-27321
}

Approved for public release; distribution is unlimited.

Title:

Ballistic Missile Defense

Author(s): $\quad$ McDuff, George Glen

Intended for: Weapons Engineering Study Hall

Issued: 
Disclaimer:

Los Alamos National Laboratory, an affirmative action/equal opportunity employer, is operated by the Los Alamos National Security, LLC for the National Nuclear Security Administration of the U.S. Department of Energy under contract DE-AC52-06NA25396. By approving this article, the publisher recognizes that the U.S. Government retains nonexclusive, royalty-free license to publish or reproduce the published form of this contribution, or to allow others to do so, for U.S. Government purposes. Los Alamos National Laboratory requests that the publisher identify this article as work performed under the auspices of the U.S. Department of Energy. Los Alamos National Laboratory strongly supports academic freedom and a researcher's right to publish; as an institution, however, the Laboratory does not endorse the viewpoint of a publication or guarantee its technical correctness. 


\title{
Ballistic Missile Defense
}

\author{
by Dr. Glen McDuff \\ Los Alamos National Lab \\ P.O. Box 1663 \\ Los Alamos, NM 87544
}

\begin{abstract}
A quick look at ballistic missile defense, BMD, from its beginnings in WWII with the Nazi V2 to the proposed hypersonic delivery vehicle is presented. As BMD is one of the most, if not the most difficult of technological challenges, we assess the meager successes and plentiful disappointments. Not to be too discouraging, a fleeting review of the incredibly successful and expensive ( $\$ 800$ billion) air defense systems constructed by the U.S. in the 50's and 60's is reviewed. Finally, current and future BMD schemes a examined.
\end{abstract}




\section{Ballistic Missile Defense}

By

Dr. Glen McDuff

Presented at

Weapons Engineering Study Hall

LAUR-18-XXXXX 


\section{Disclaimer}

- Please excuse any inaccuracies in exact numbers of assets

- Depending on who you ask or what agency website you visit, numbers and predicted performance of defensive systems varies greatly. 


\section{The First Ballistic Missile}

- Quiz? When?

- Answer

Ancient times with the invention of trebuchets and catapult projectiles, there was no defense against the ballistic projectile

- The first modern ballistic missile came in 1944, the $\mathrm{V}-2$, velocity $4-5 \mathrm{~km} / \mathrm{sec}$, impact at about $3 \mathrm{~km} / \mathrm{sec}$,

- The Brits had about 25 seconds to detect, determine trajectory, velocity, position, and target the V2

- AND launch an interceptor with; velocity, accuracy, and the agility to hit the $\mathrm{V}$-2 


\section{The First Ballistic Missile}

- Quiz? When?

- Answer

Ancient times with the invention of trebuchets and catapult proiectiles there was no defense against the hallistic

- Tr The British were smart enough $\mathrm{V}$

\section{not even to try}

- The Brits had about 25 seconds to detect, determine trajectory, velocity, position, and target the V2

- AND launch an interceptor with; velocity, accuracy, and the agility to hit the $\mathrm{V}$-2 


\section{The Ballistic Missile Plague}

- The U.S. immediately started considering missile defense after WWII with Project Wizard

- In 1949 the U.S. embarked on an aggressive program of rocket development and missile defense

- They quickly realized missile defense is......well

- On a scale from 1-10

atomic weapon development $=2$

rocket development $=7$

mission to the moon $=10$

missile defense $=165$ 


\section{The Ballistic Missile Plague}

- "By the 1960's the U.S. still had no defense against even the crude V-2"

- Several deficient technologies were hampering missile defense

1. Detection - radars

2. Computing - command and control/signal processing

3. Targeting - radars and computing

4. Interceptor agility and speed - rockets science 


\section{What can we do?}

- Let's take a short look at aircraft defense

- In 1951, a plan to defend the U.S. against Soviet bomber attack was conceived.

- By 1963 and \$800 billion (2018 \$) later

$300+$ radars, on land, sea, air, and artic based

24 direction centers, called DC, and

3 combat centers

- Became operational as the

Semi-Automatic Ground Environment System....SAGE 


\section{SAGE}

- Early warning radar detects approaching aircraft

- Radar reports automatically transmitted to a Direction Center (DC) via phone lines

- DC processes data

- Air bases, HQs, and missile batteries notified

- Data relayed between DC and adjoining centers

- DC assigns interceptor aircraft and vectors interceptors to targets

- Interceptors rendezvous with and confront the target aircraft 


\section{SAGE}

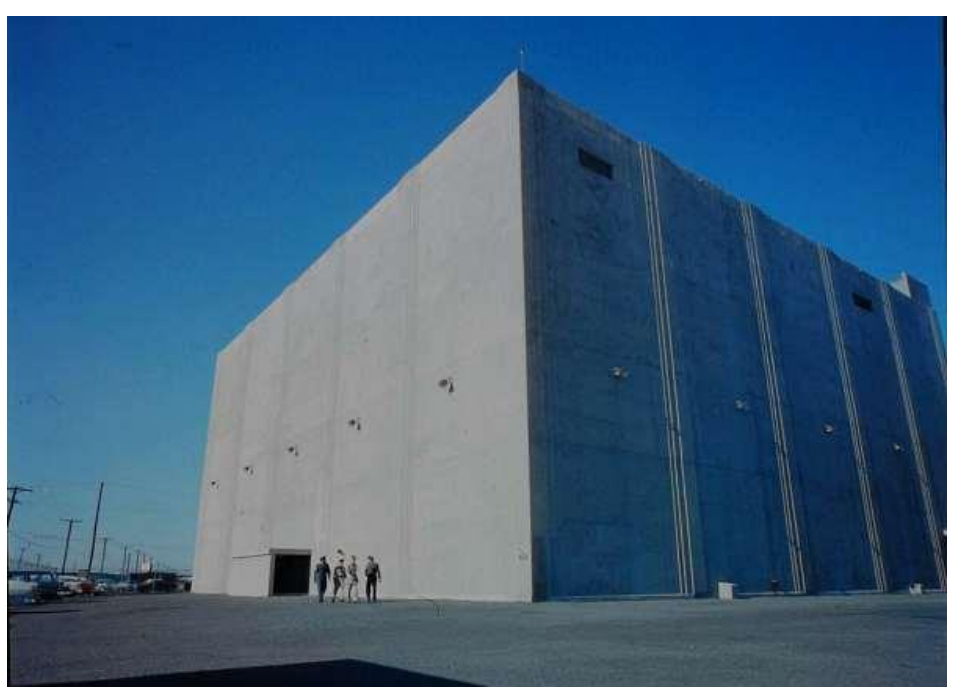

The two computers covered 15,000 sq ft, had 120,000 vacuum tubes, 256kB memory, weighed 500 tons and exhausted $6 \mathrm{MW}$ or $20 \mathrm{Mbtu}$. That was enough to heat over one million sq ft of adjacent base.

\section{- Los Alamos}
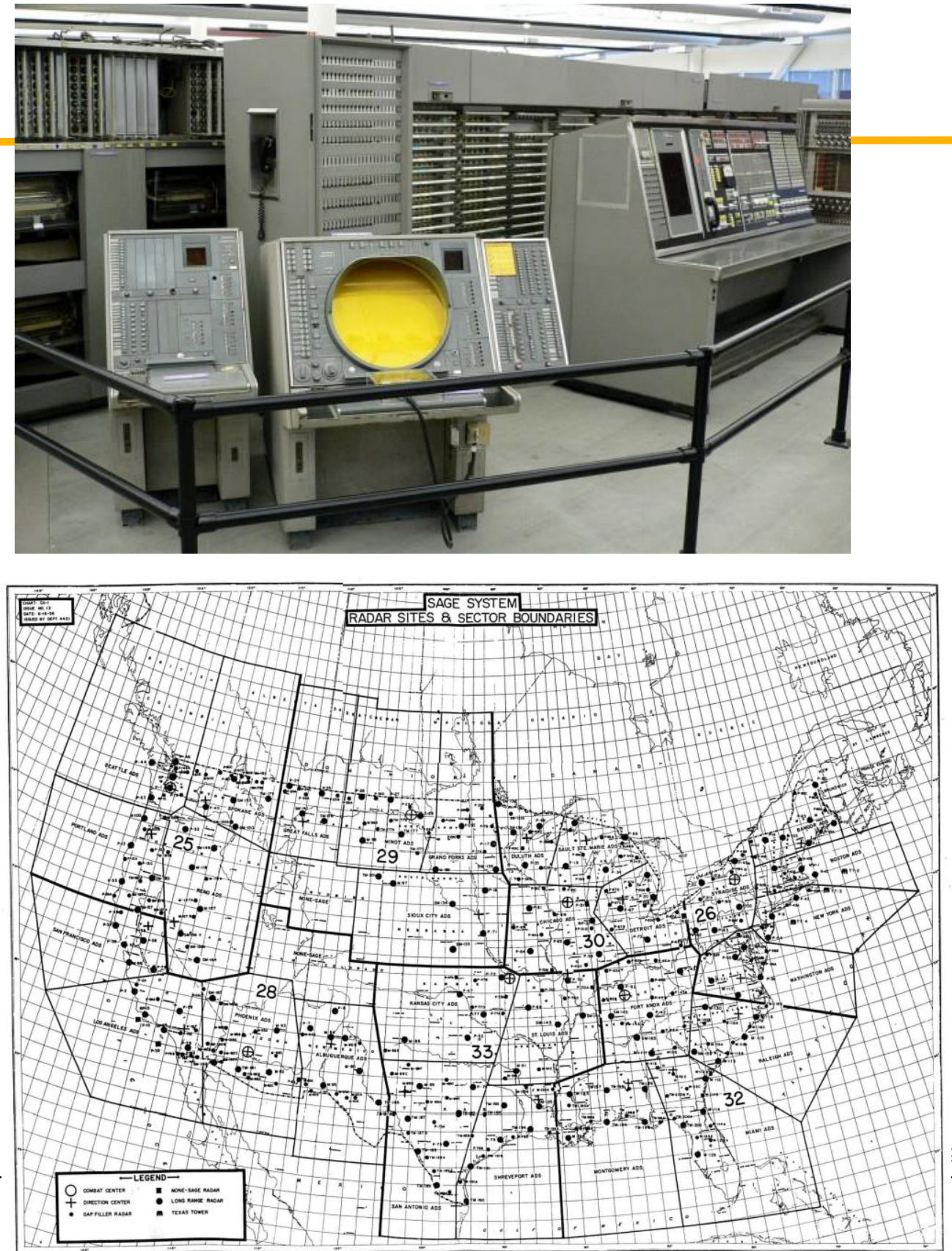


\section{The Birth of 20,000 Weapons}

- 12 January 1953 - Special Weapons Development Committee determined that tens of thousands of air defense missiles would be required to defend the U.S. against a massive Soviet attack

- 14 January 1953 - The Joint Air Defense Board concluded that the U.S. needed 40,000 air defense missiles

- 25 August 1953 Los Alamos Scientific Lab introduced the design of three new sealed warheads* for high altitude applications, a first in nuclear warfare 


\section{You don't always get what you want}

- Meetings at Los Alamos with the Joint Air Defense Board and the DMA, Division of Military Applications* resulted in the following request:

- A warhead that has infinite shelf life, once made ready, can stay ready for several months, and have "as much maintenance as a block of pine"

- The W25, W30, and W31 had a three year shelf life(not bad), could remain ready for over three weeks,(OK) and were hermetically sealed, "took as much maintenance as a block of wood"

- These were known as the "wooden bombs" 


\section{Air Defense Missiles}

- Nike Hercules $\approx 25,000$

- Talos $\approx 1500$

- Bomark $\approx 570$

- Genie $\approx 6000$

- Falcon $\approx 26,000$

- Honest John $\approx 7000 *$
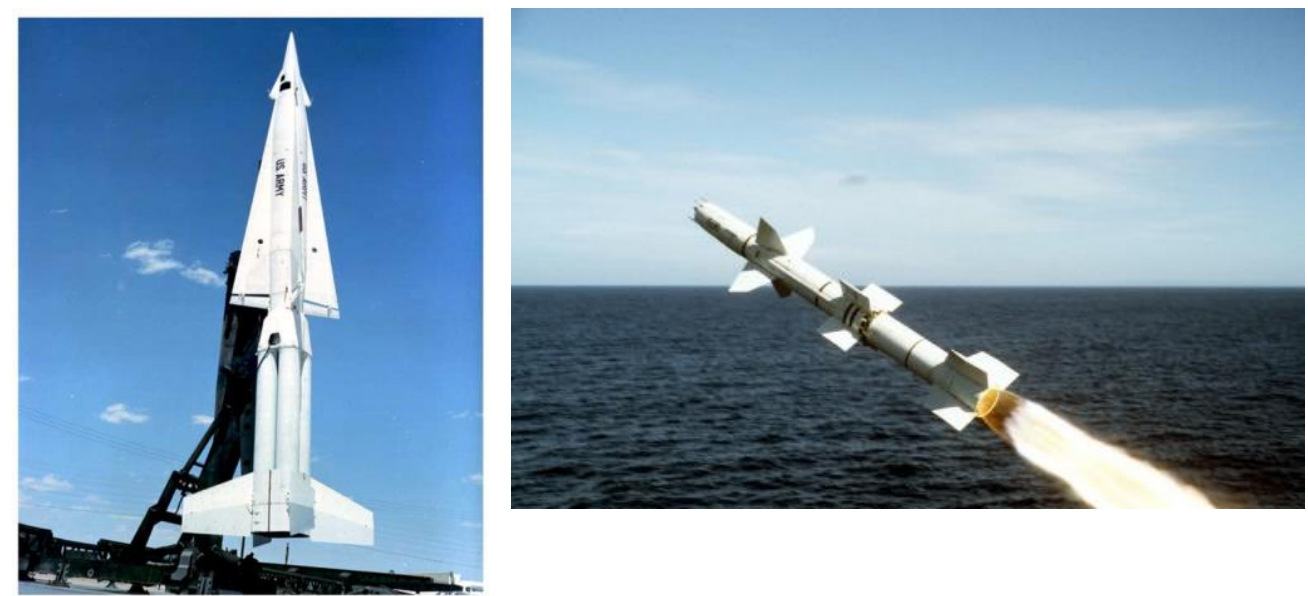

\section{$\sqrt{2}$}
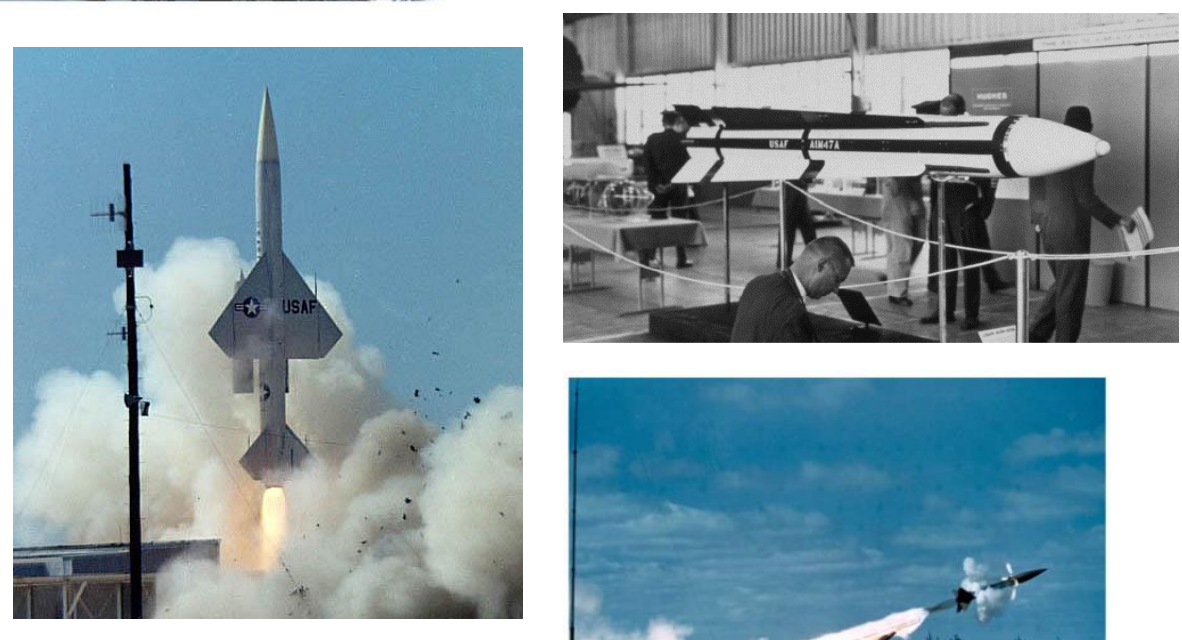


\section{Air Defense Missiles}

\section{U.S. Nuclear Weapons Stockpile, 1945-2009*}

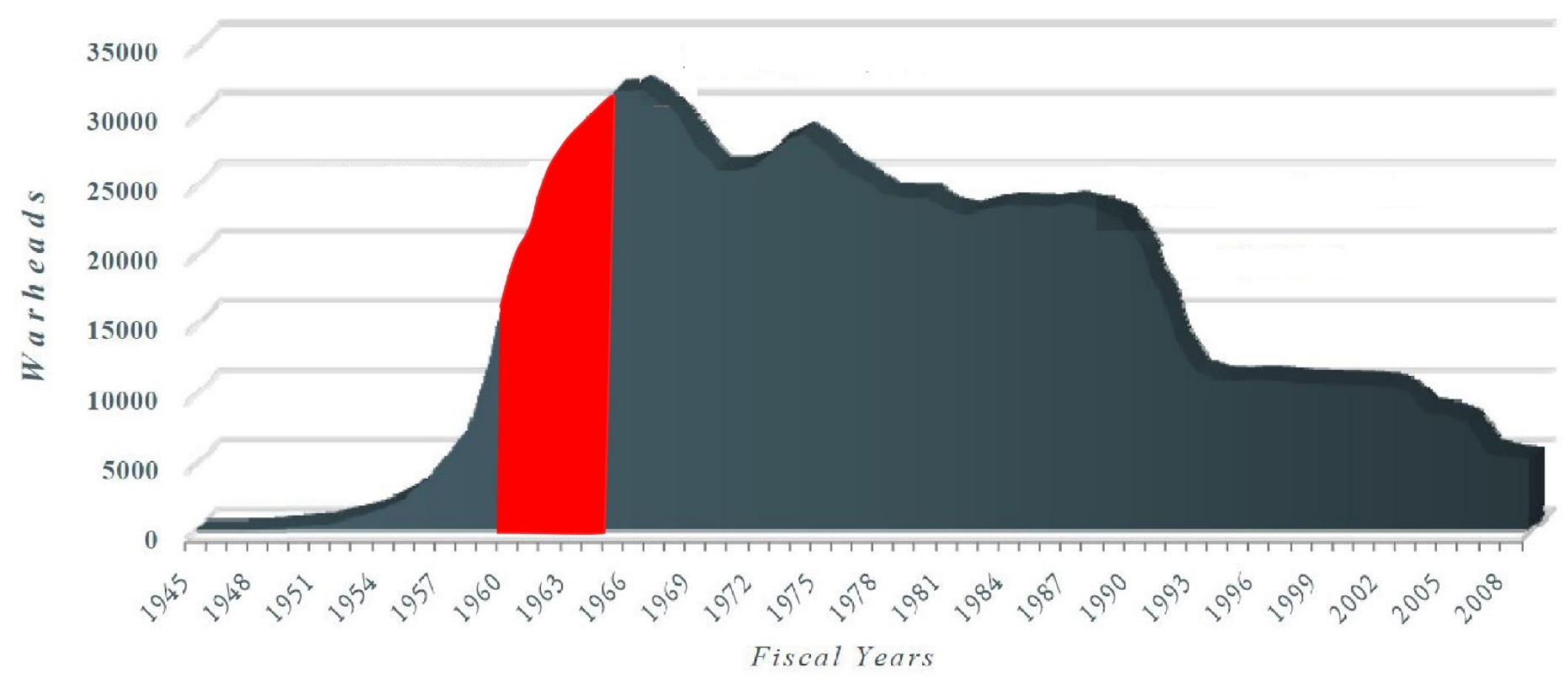

But what about missile defense? 


\section{Missile Defense History}

- Missile defense timeline

Nike-Zeus

Project Defender

Sentinel Project and Safeguard System

Strategic Defense Initiative Origination...Star Wars

BMDO

Defense Support Program and currently

Space Based Infrared System, the SBIRS
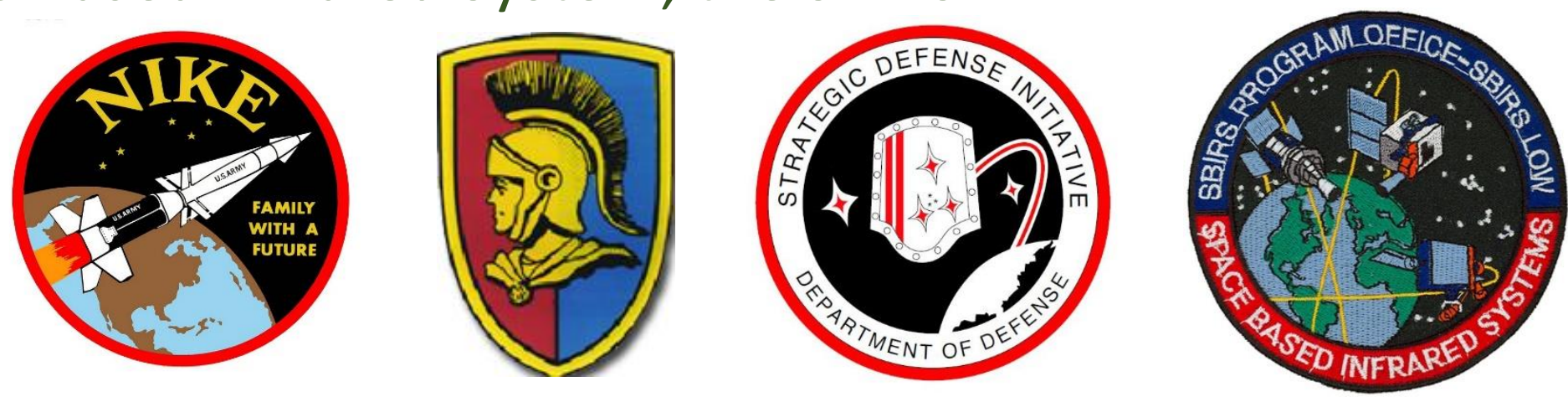


\section{Star Wars 23 March 1983}

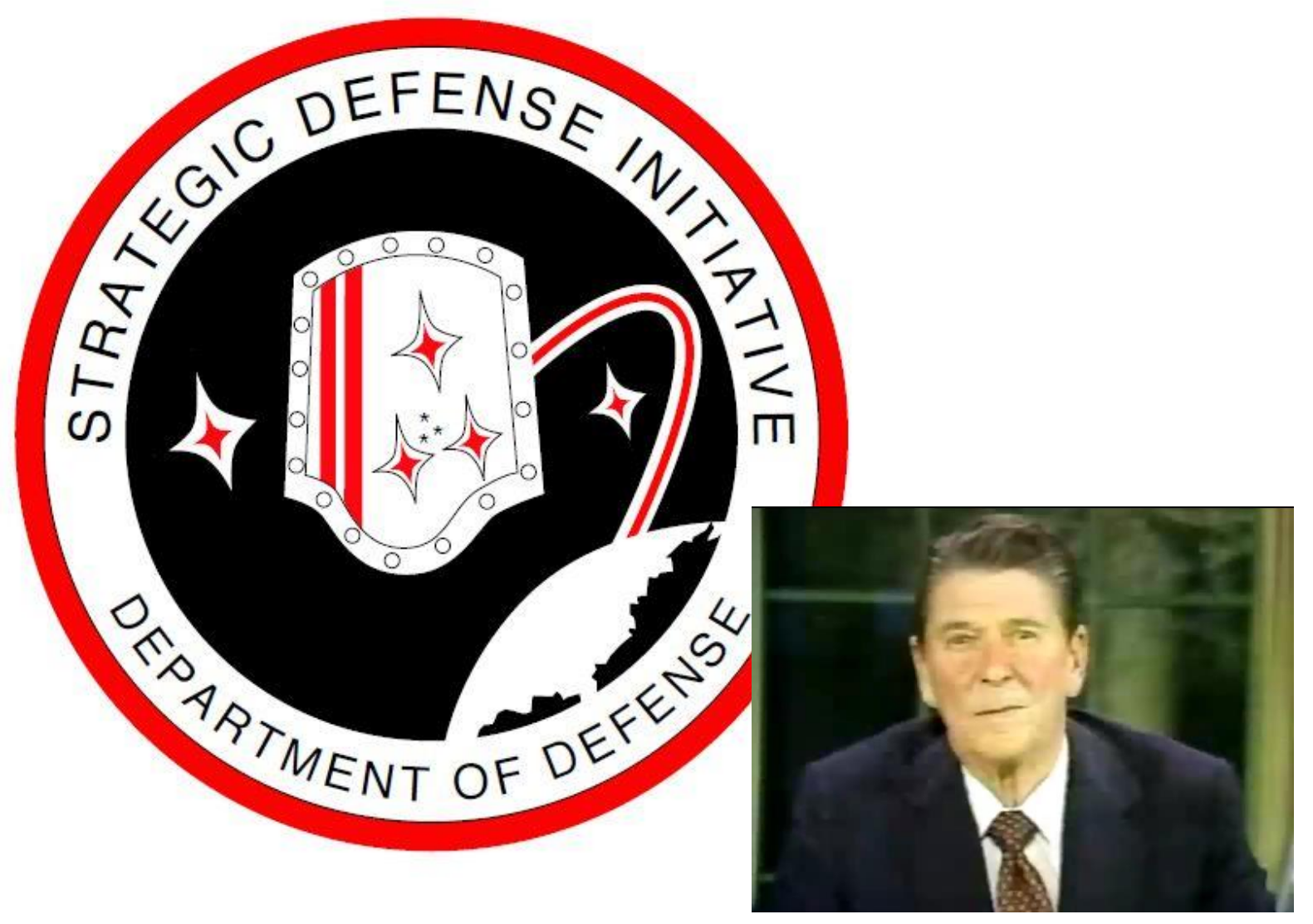




\section{Our First Success}

\section{NIKE-ZEUS SYSTEM}

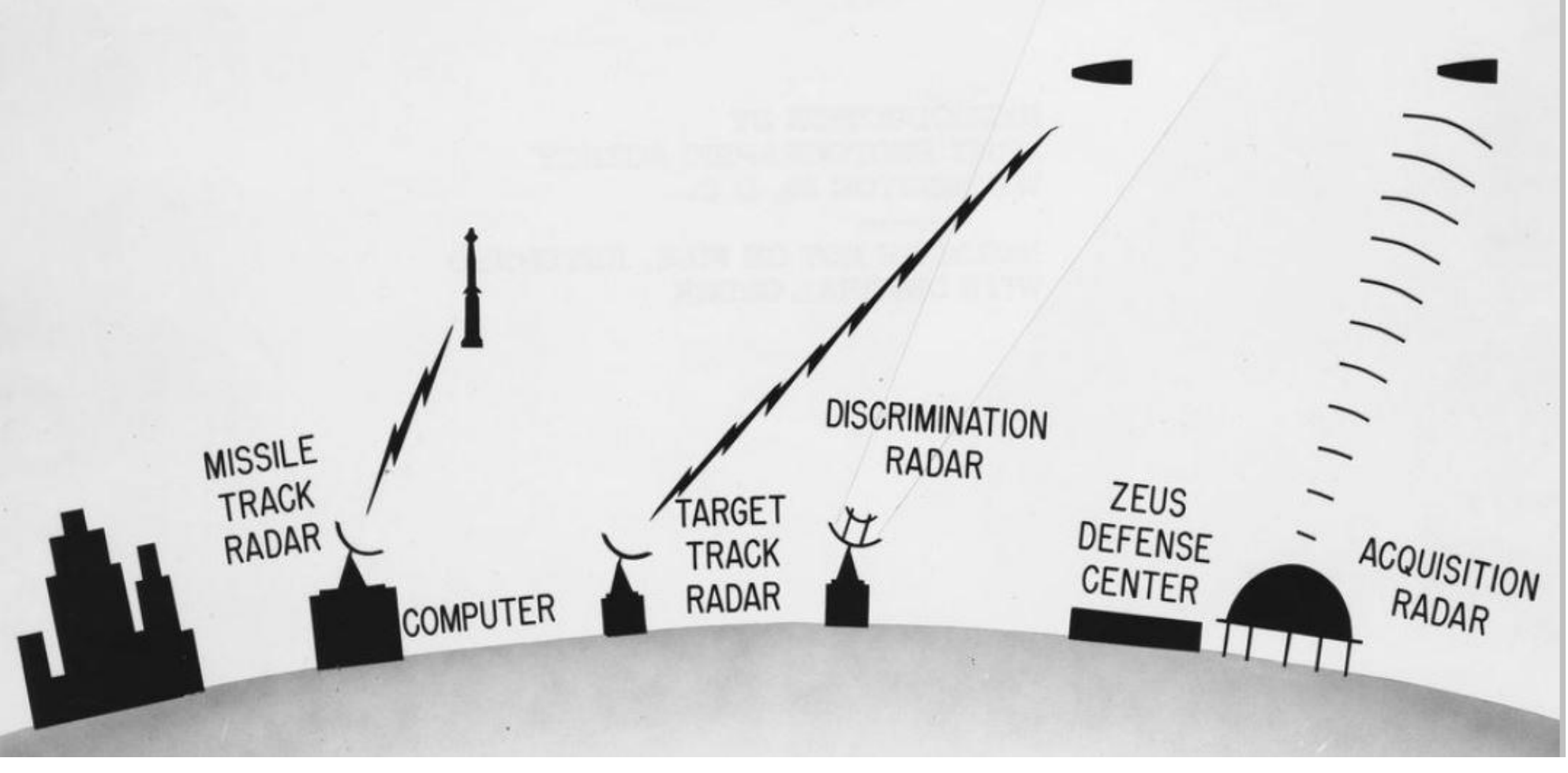




\section{Effectiveness}

- Nike Zeus was fairly effective against ONE warhead on one missile, such as the early U.S. ICBMs

- But with the advent of multiple warhead missiles, even those that are not independently targetable, MIRV, the effectiveness of Nike Zeus dropped to almost zero.

- And so was the program

NIKE-ZEUS SYSTEM

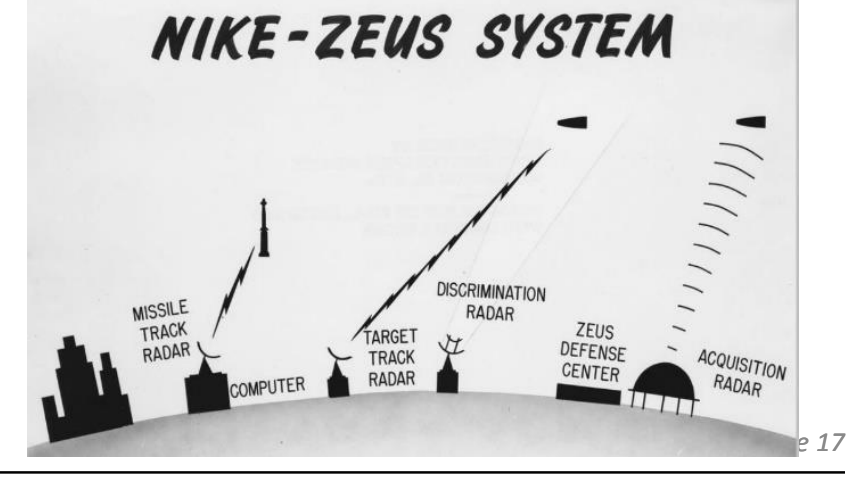




\section{Missile Defense History}

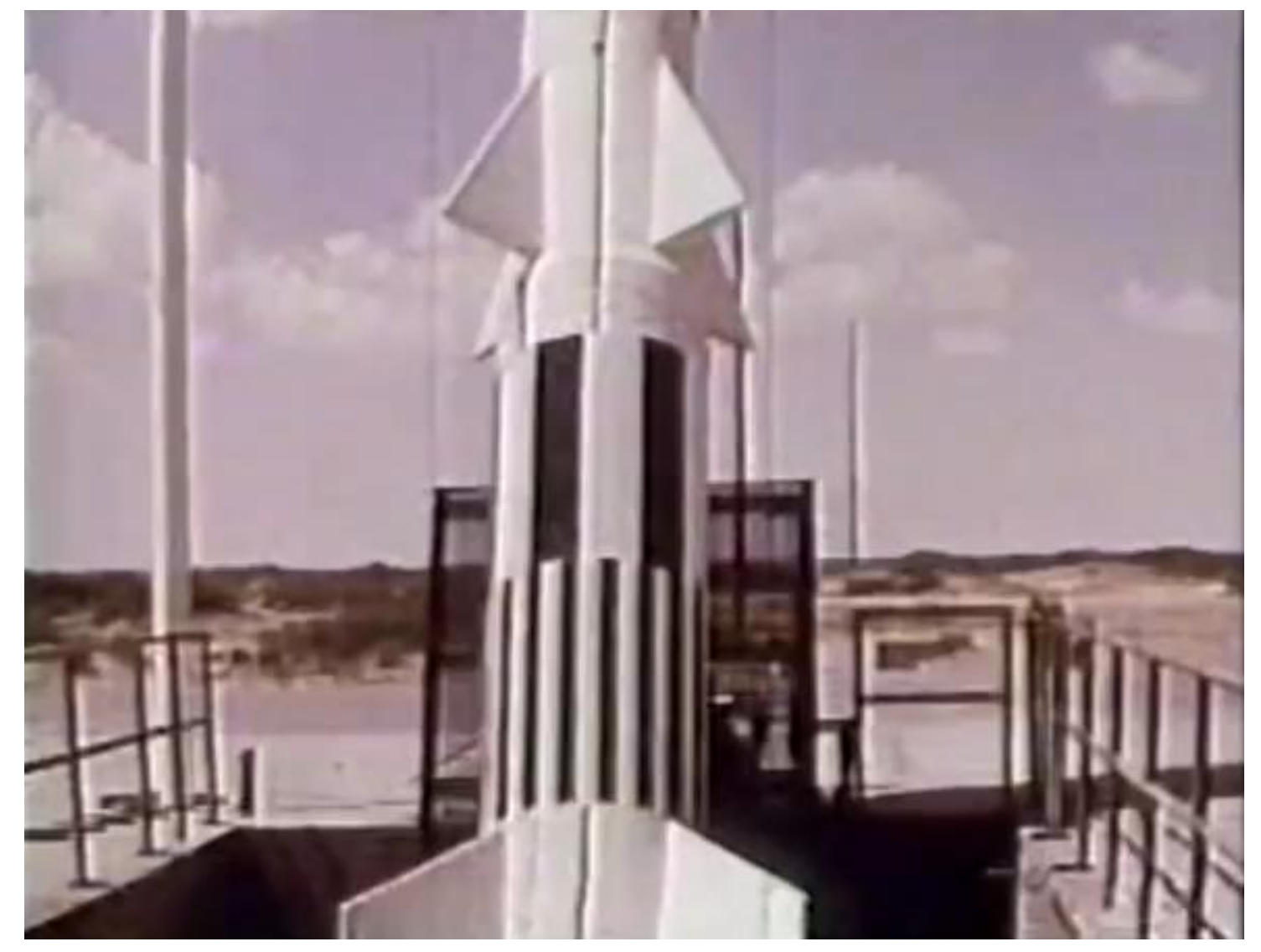




\section{The only U.S. ABM site}
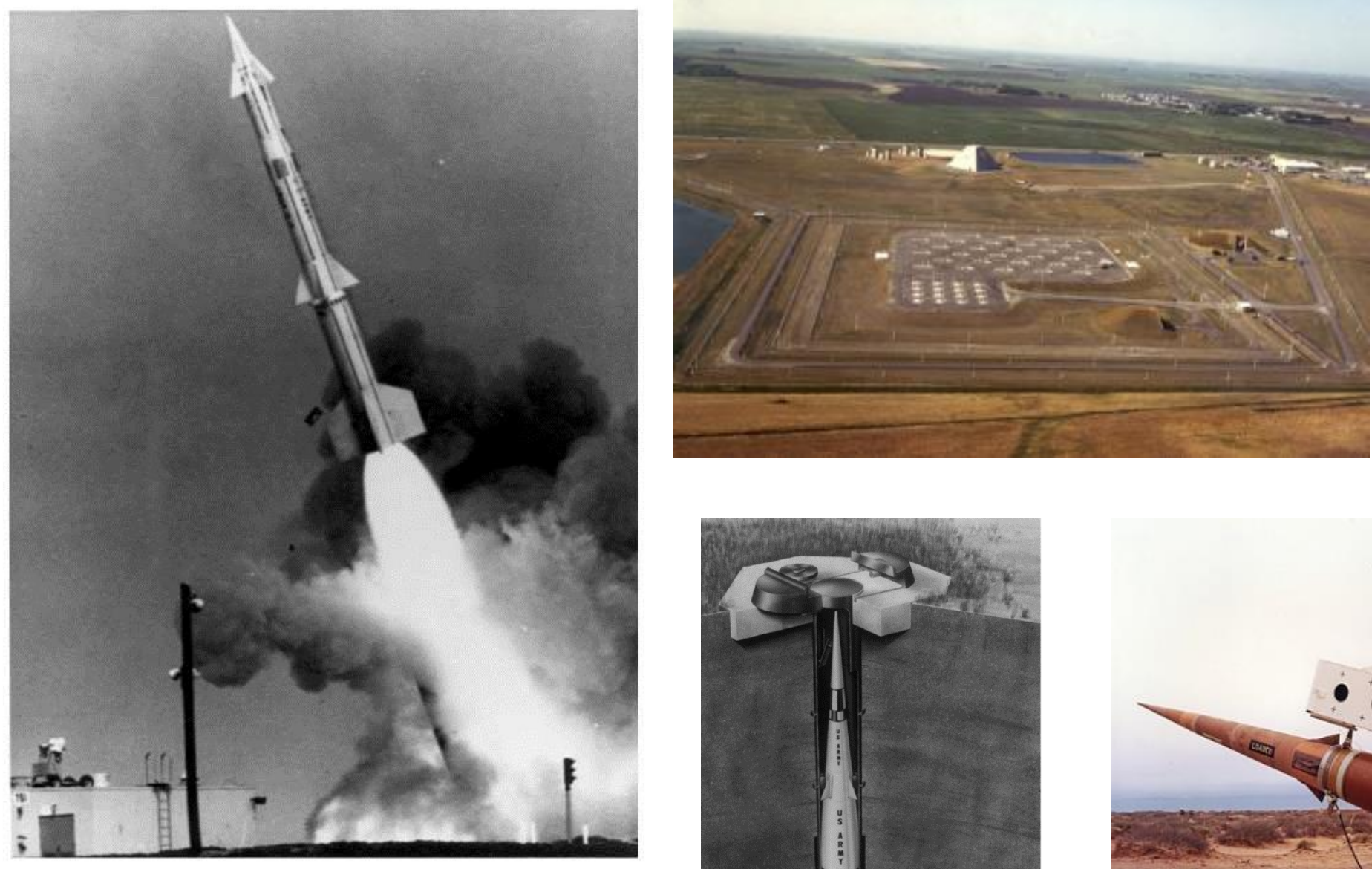

Stanley Mickelson Safeguard Complex North Dakota (The U.S. ABM site)

Sprint W-66
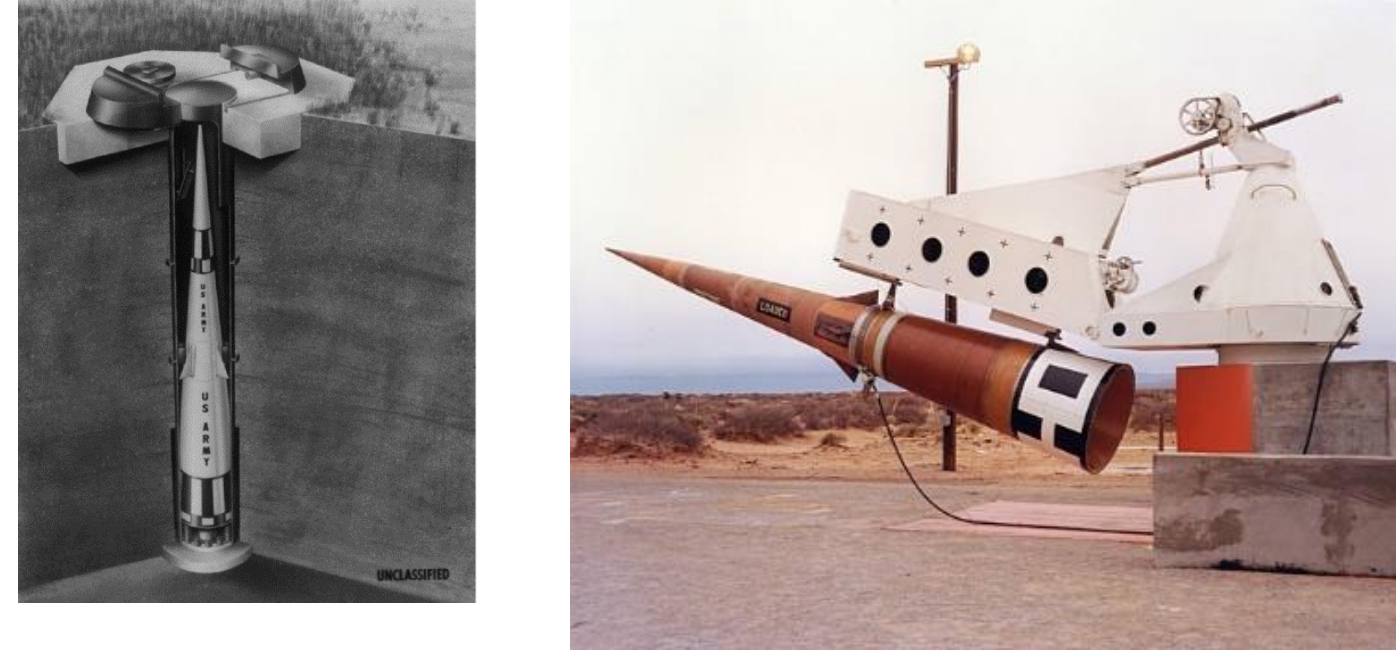


\section{The Sprint Mach 10 in 5 seconds}

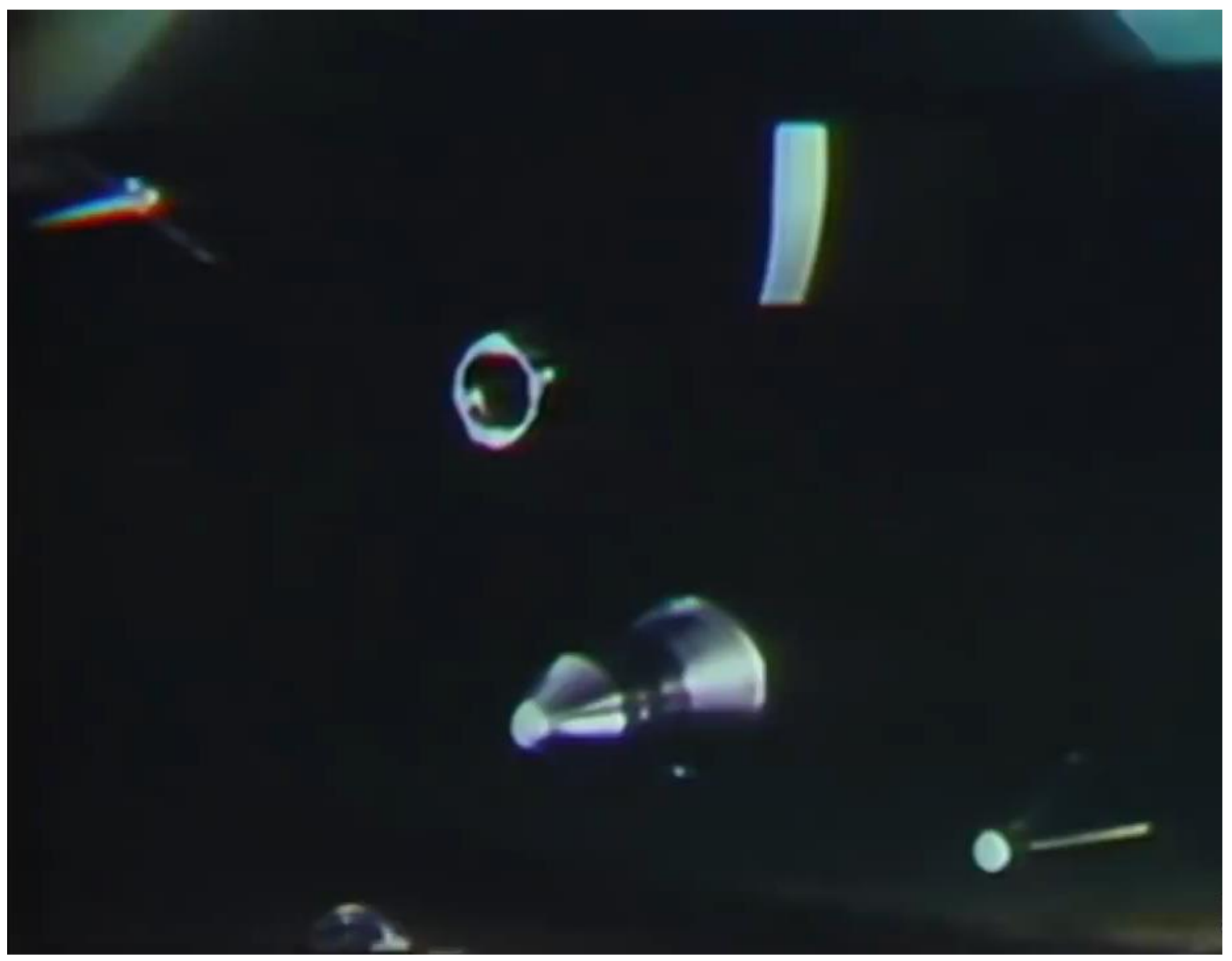




\section{Stanley Mickelsen Safeguard Complex}

- The U.S. only ABM site

- 1 Apr 1975 Achieved site readiness

- 1 Oct 1975 Became operational

- 2 Oct 1975 House of Representatives voted to decommission the base, less than 24 hours after becoming operational

- 3 Oct 1975 Decommission began

- 10 Feb 1976 Shut down

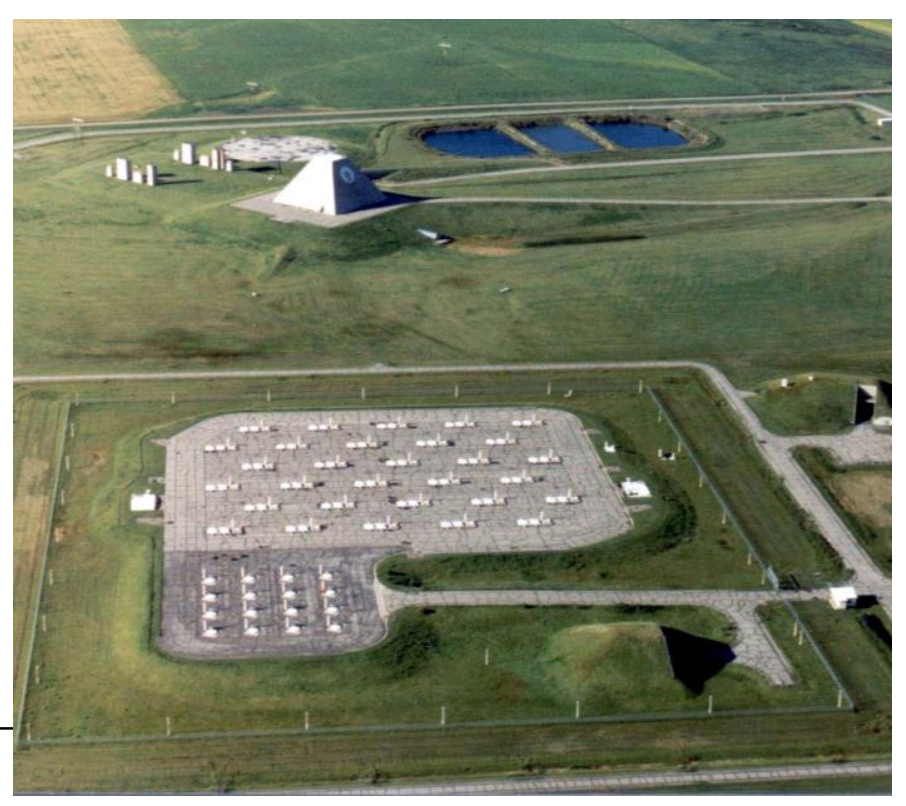




\section{Safeguard ABMs Information}

- The fact that the total number of Spartan and Sprint interceptors planned for the 4-site option at Minuteman sites is 120 Spartans and 264 Sprints. (71-3)

- The nuclear device to be tested in the Cannikin event is related to the optimum development of a warhead for the Spartan missile of our Safeguard Ballistic Missile Defense Program. The measurements of device performance which will be obtained from the test are essential to our optimum defense deployment of safeguards for protection of our Minuteman missile sites. (71-9)

- The mere fact, without elaboration, that the U.S. has had in development a long-range interceptor with a high-yield warhead which kills by X-ray, and that the missile is named Spartan. (74-4)

- The mere fact, without elaboration, that the Sprint warhead is designed to use air blast which may destroy the reentry vehicle, and neutrons which penetrate the reentry vehicle. (74-4) 


\section{Steps to Ballistic Missile Defense}

- Advanced Warning

Searching, acquiring, and tracking

- Discrimination

Real vs. decoys

- Surface Guidance

Targeting and guiding the interceptor

- Command and Control

Coordinating all the detection, targeting, launching, etc.

- Anti-ballistic missile

These are no ordinary missiles 


\section{Step 1 Advanced Warning}

- Advanced Warning

Searching, acquiring, and tracking

- These technologies have varied over the years

- Ground and satellite based radars

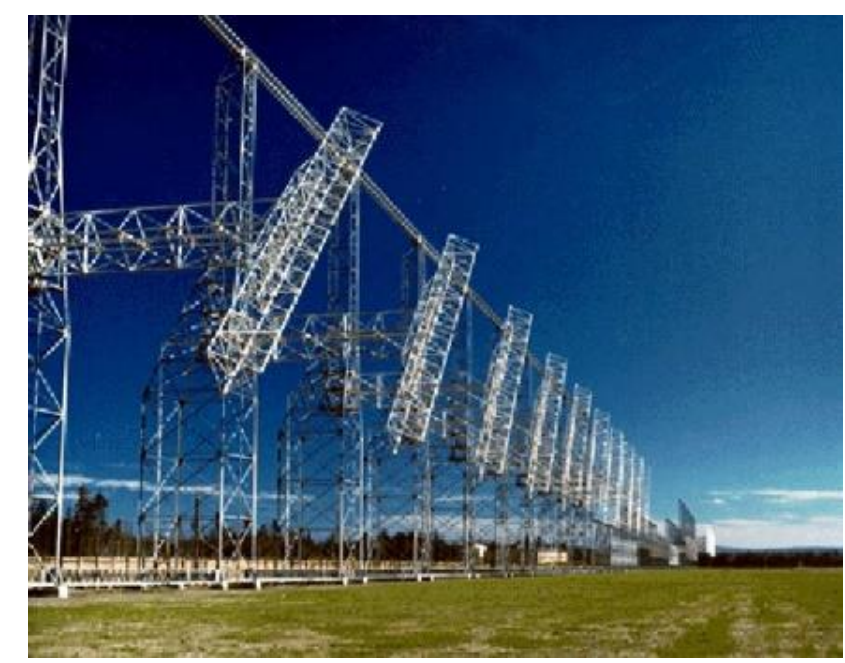

AN/FPS-118 over-the-horizon radar

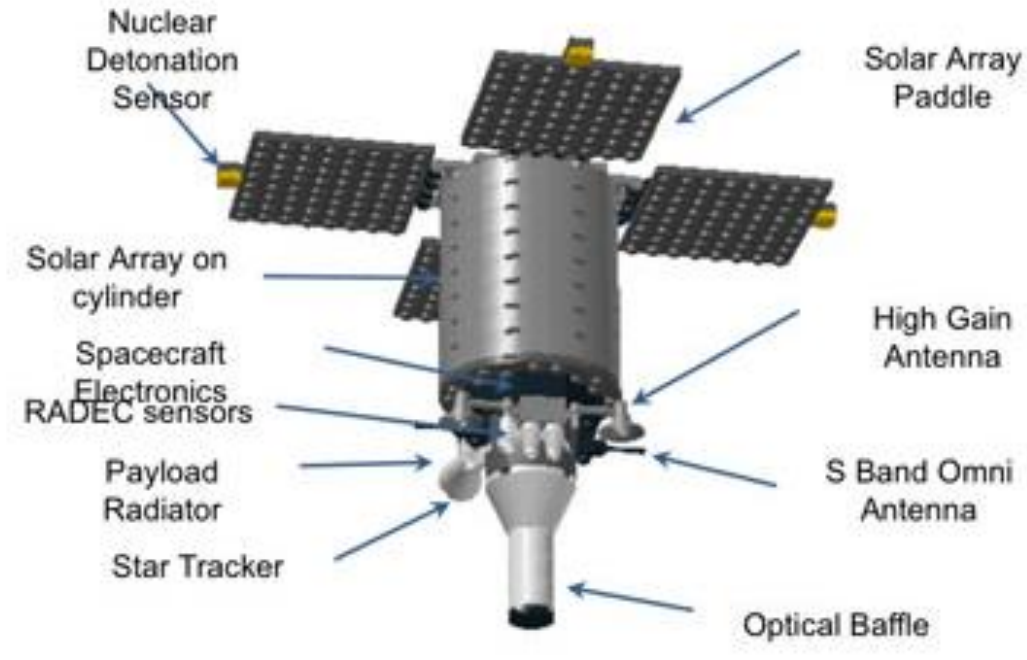

Defense Support Program, DSP Satellite 


\section{Spaced Based Infrared System}

- Consist of 4 geosynchronous satellites

- The NEW system 


\section{Step 2 Discrimination}

- Sea and land based radars

Low frequency locate items

High frequency, $x$-band, higher definition

- Currently we use only terrestrial based radars

- You really need space based radars or lidars for several reasons

No atmospheric distortion or power absorption

Much greater field of view, essentially from launch to impact

Tracking from third stage to warhead deployment 


\section{Step 3 Surface Guidance}

- To guide the interceptor to the target

- Often considered are "beam riding" missiles

- Beam riders have limited agility to avoid unwanted collisions

- This takes massive computing power, high bandwidth and low noise signals

- Remember you may have 100,000 items in which to guide your missile to the correct one. 


\section{Step 4 Command and control}
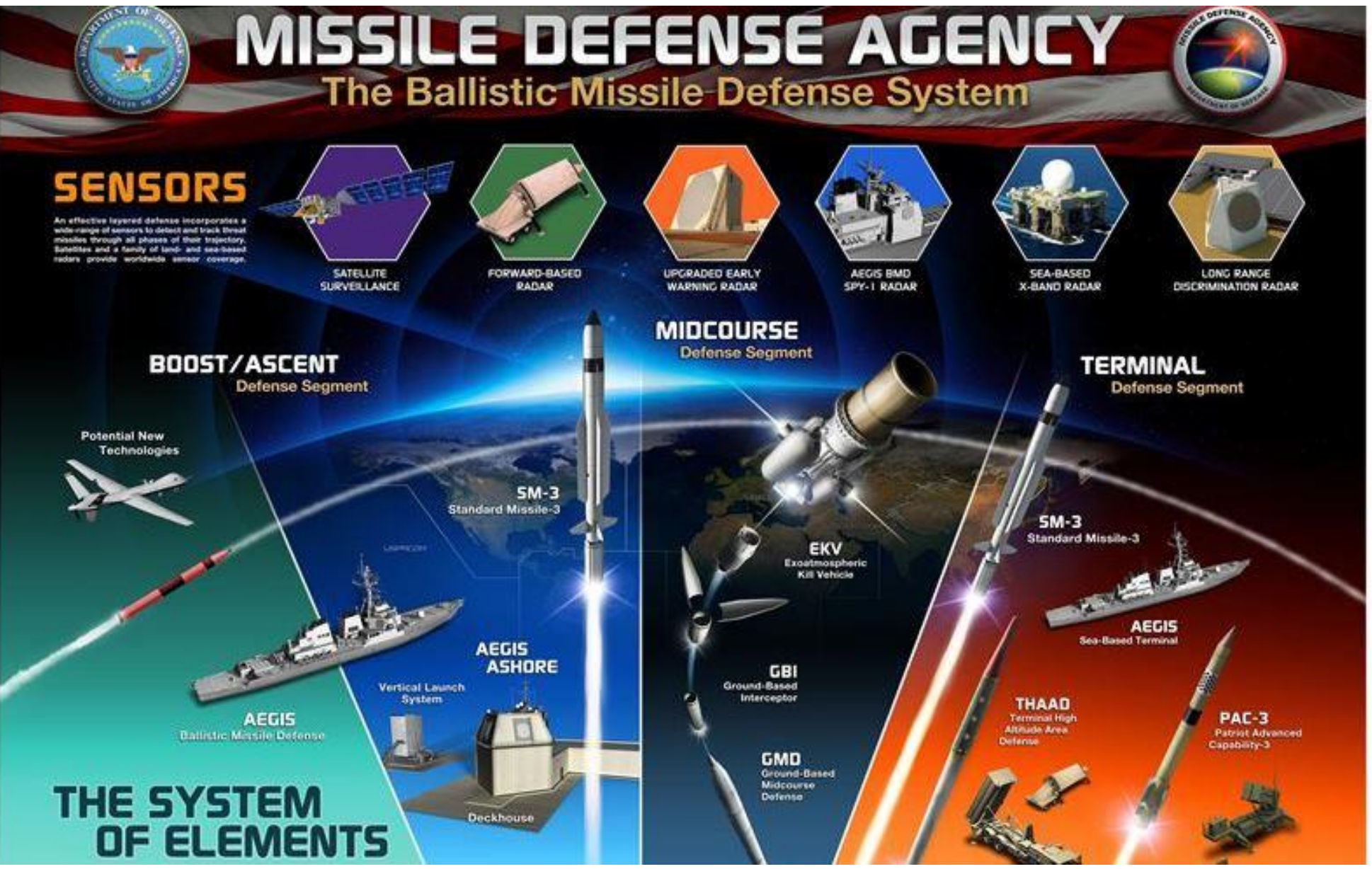


\section{Step 4 Command and control}

- Coordinate all this...

AN/SPY-1 Radar

Cobra Dane (1976 radar in the Aleutian Island)

Command and Control, Battle Management, and Communications

(C2BMC)

Defense Support Program (DSP)

GMD Fire Control and Communication

Ground-based Interceptor (GBI)

Long Range Discrimination Radar (LRDR)

Sea-based X-band Radar (SBX)

Space Tracking and Surveillance System (STSS)

Space-based Infrared System (SBIRS)

TPY-2 X-band Radar

Upgraded Early Warning Radar (UEWR) 


\section{Step 5 The ABM}

- Currently we have

- PAC-3 for SRBM (300-1000km)

Patriot Advanced Capability

- THAAD MRBM (1000-3000km)

Terminal High Altitude Terminal Design

- Aegis

SM-3 IA MRBM (1000-3000km)

SM-3 IB IRBM (3000-5500km)

SM-3 IIA ICBM (> 5500km)

- GMD or Ground-based Midcourse Defense EKV ICBM (>5500km) Exo-atmospheric Kill Vehicle 
PAC-3

- PATRIOT Advanced Capability-3

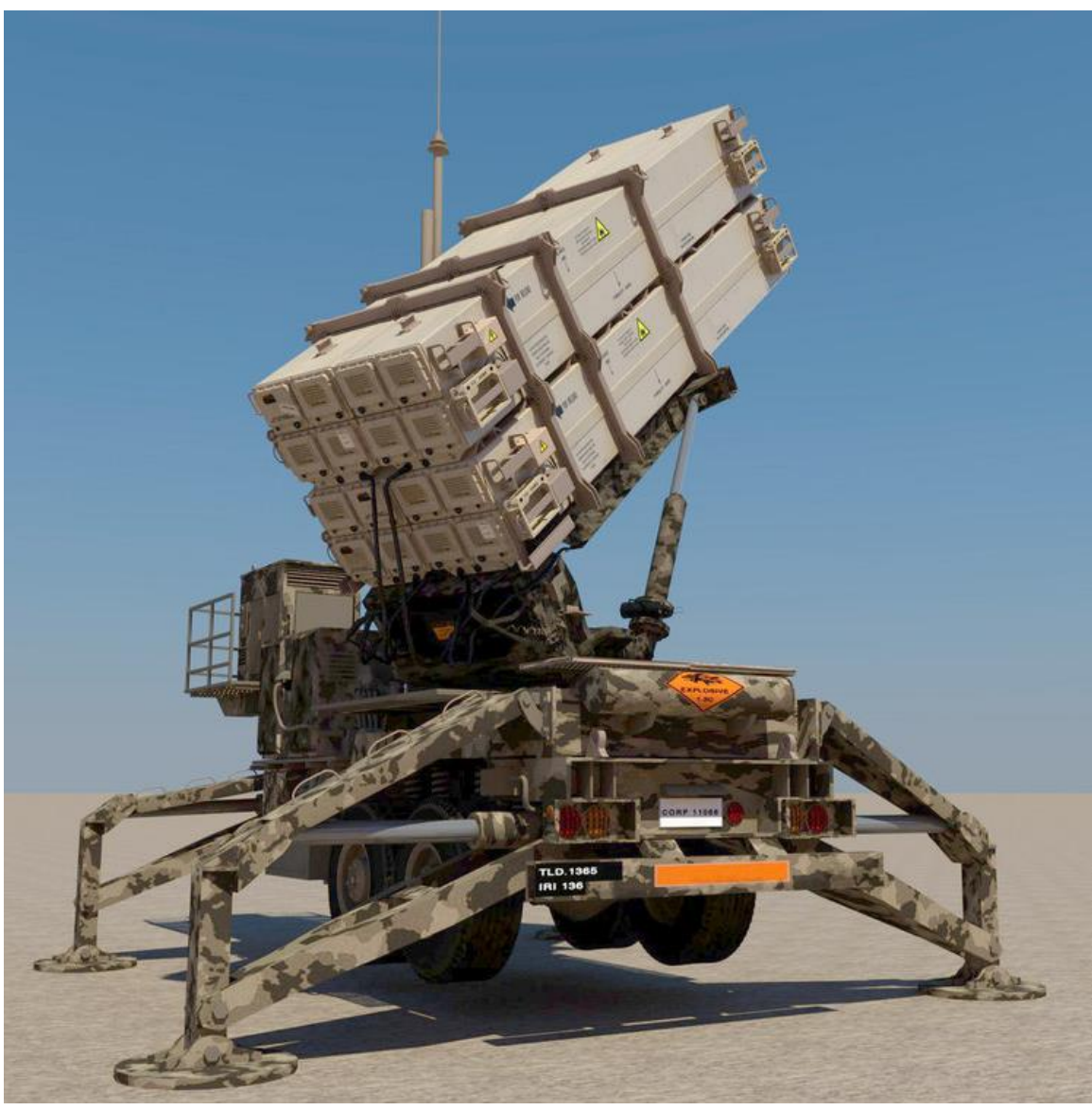
EST. 1943 
THAAD

- Terminal High Altitude Area Defense

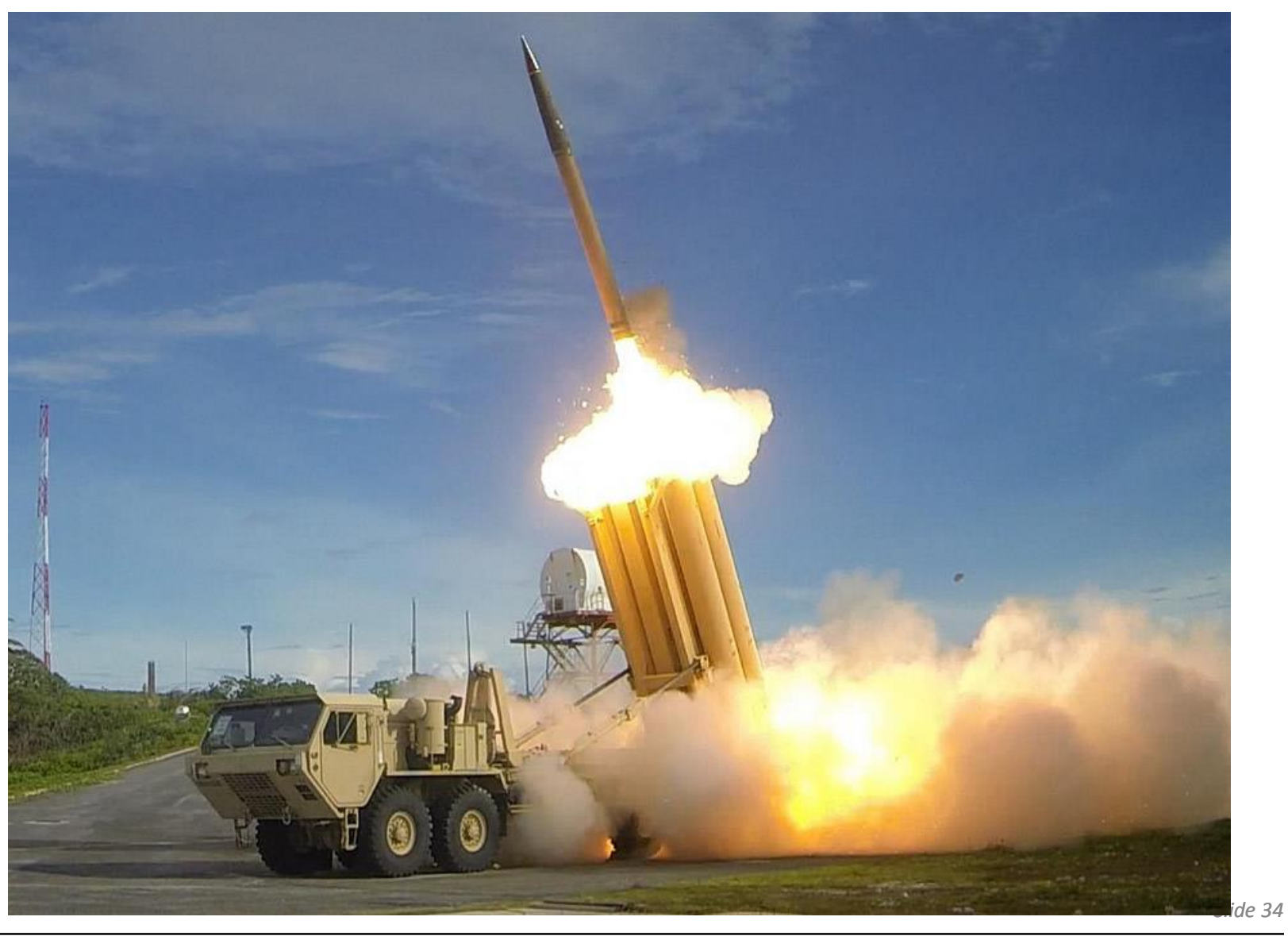




\section{Aegis BMD System}

- Both land and sea deployed

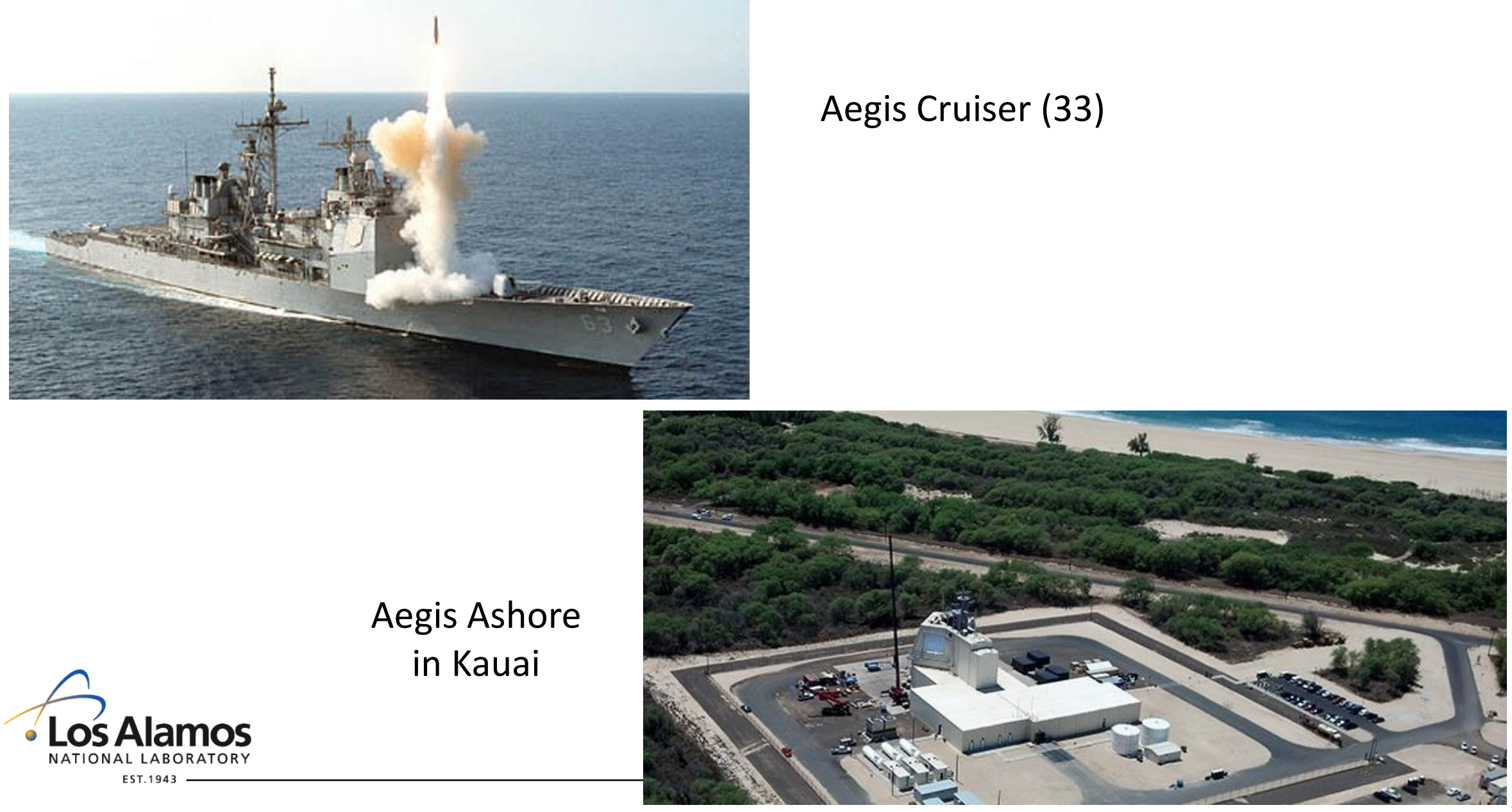




\section{Aegis Missiles}

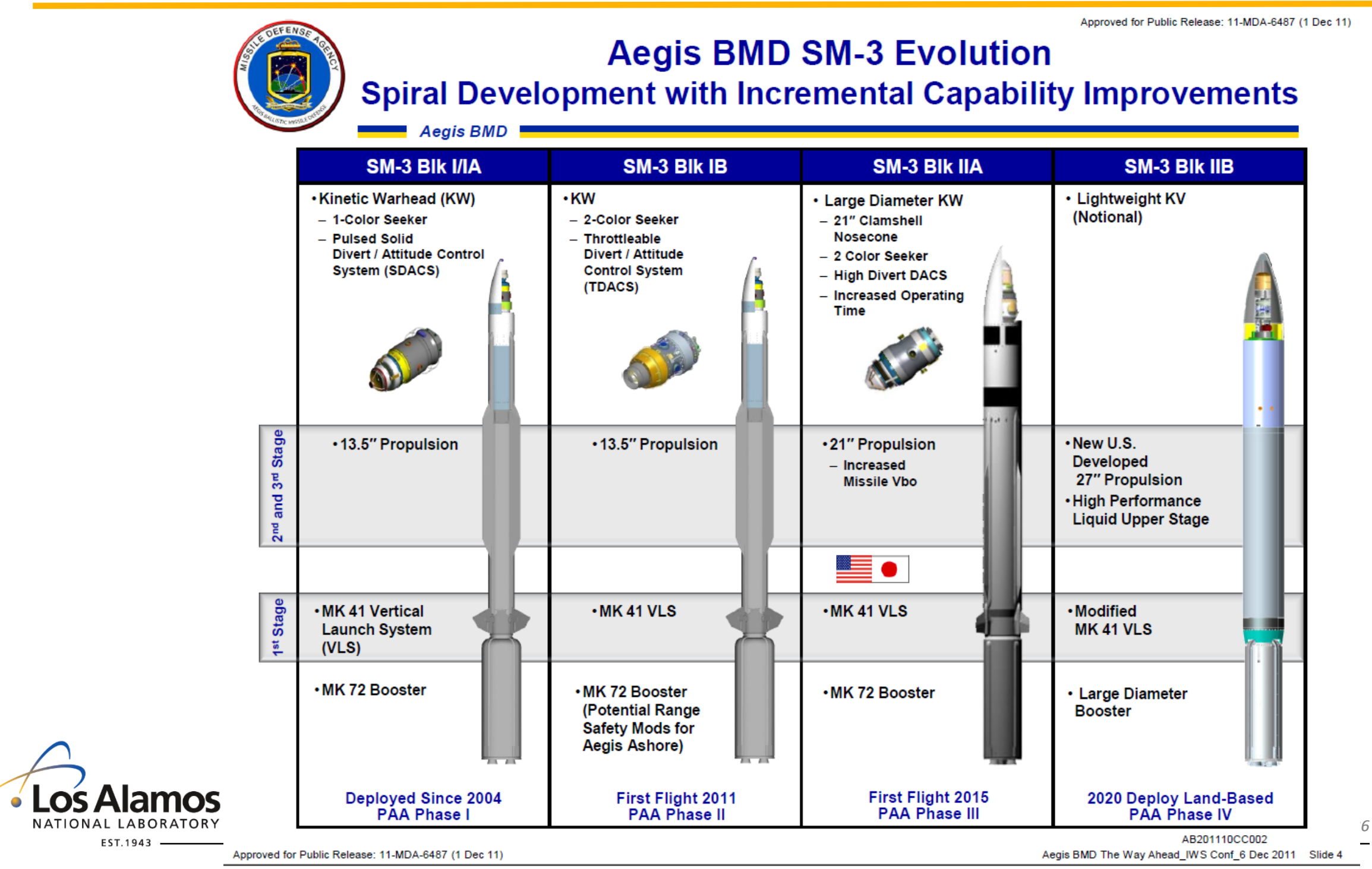




\section{GMD}

- Ground Based Midcourse Defense with the EKV - exo-atomospheric kill vehicle

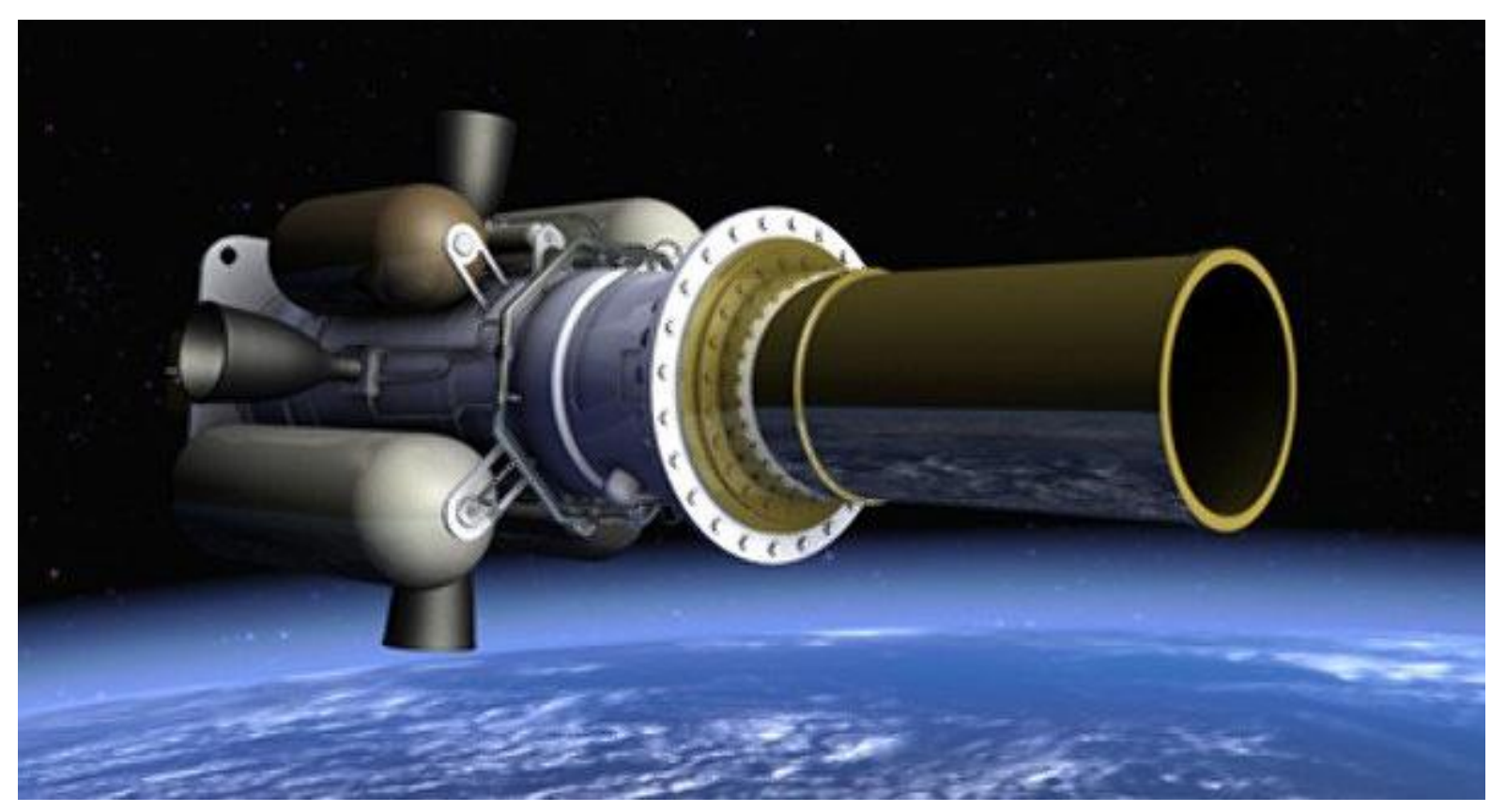




\section{The Target}

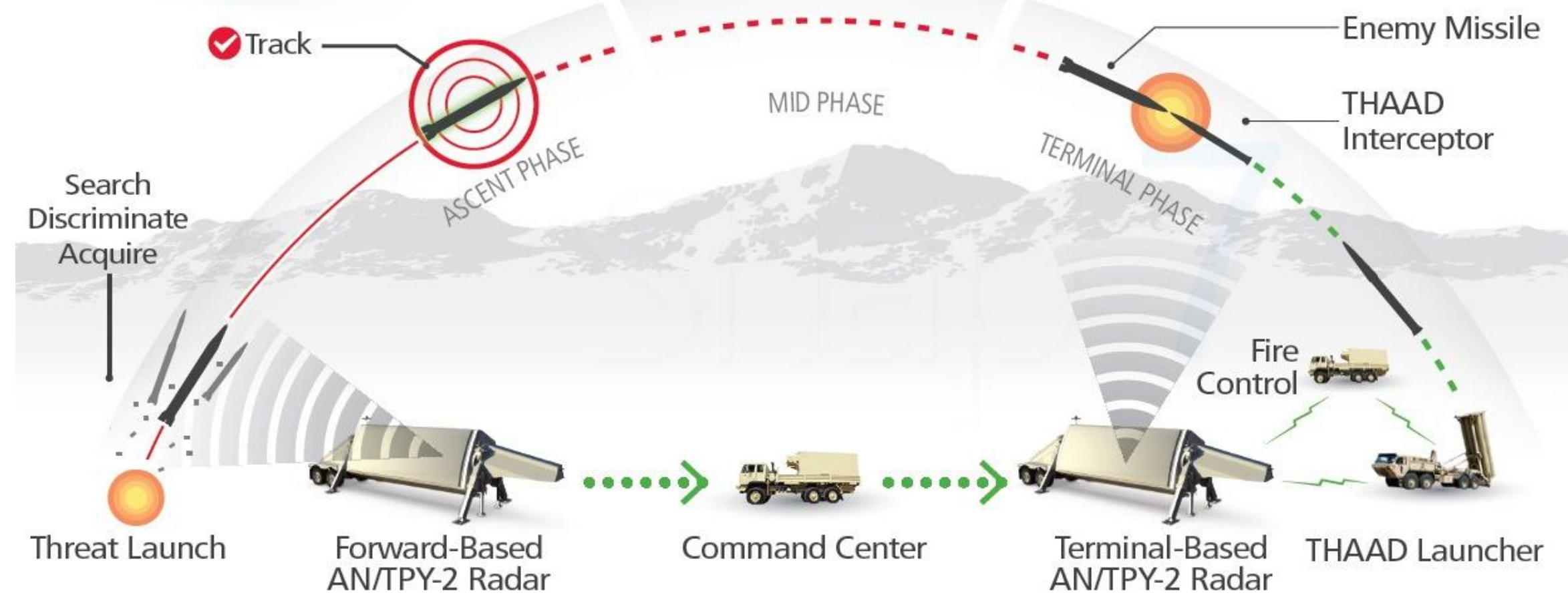




\section{Now the tricky part}

- Boost Phase

1-5 minutes duration

Easiest to detect, rocket launch

Difficult to kill because of short duration and your missile site must be close to the launch site

- Midcourse

10-20 minutes duration

Exo-atmospheric

Track and discriminate target from decoys and debris (everything ejected from the spacecraft) 


\section{Midcourse gets really messy}

- In the midcourse phase, everything launched into space is going to travel with the warhead targets.

- This can include the entire $3^{\text {rd }}$ stage, heat shields, warhead covers, fuel tanks, etc. creating massive debris field.

- On top of all this, the adversary can deploy optical and EM countermeasures. This can be anything from small metal stamps, to reflective powders, to the worse, the decoys! 


\section{Decoys are no SECRET}

\section{United States Patent}

Lew et al.

\section{[54] DECOY DEPLOYING ICBM WARHEAD}

[76] Inventors: Hyok S. Lew, 7890 Oak St., Arvada, Colo. 80005; Michael Stranahan, P.O. Box 15, Woody Creek, Colo. 81656

[21] Appl. No.: 623,453

[22] Filed: Jun. 22, 1984

[51] Int. Cl. …................... F42B 13/00; F42B 13/50

[52] U.S. Cl. .................................. 102/489; 102/505;

[58] Field of Search ................ 89/1.11; 102/340, 342 $102 / 351,357,489,501,505,506 ; 343 / 18$ B, 18

E; $244 / 3.1,14,160 ; 342 / 5,12$

[56]

References Cited

U.S. PATENT DOCUMENTS

3,916,794 11/1975 Mayer

Romer et al. .........u-u.u.u. 102/48

$4,167,009$ 9/1979 Schwartz ................... 102/351

4,340,197 7/1982 Campbell ..................................... 244/3.1

4,345,254 8/1982 Skomal .................................. 343/18 E

4,357,611 11/1982 Skomal ............................. 343/18 E
[11] Patent Number: $\quad \mathbf{4 , 8 2 9 , 9 0 5}$

[45] Date of Patent: May 16, 1989

Primary Examiner-Harold J. Tudor

[57]

ABSTRACT

This invention relates to an ICBM warhead including a plurality of warheads wherein at least one warhead includes a plurality of dummy warhead shells having an external configuration matched to the real warhead and a radar image resembling the radar image of the real warhead. The stacks of these dummy warhead shells are attached to one or both extremities of the real warhead in a coaxial relationship thereto and secured together forming a package comprising a plurality of dummy warhead shells and a real warhead, which package includes means for separating the dummy warheads and real warhead from each other after the ICBM warhead is launched into space. The dummy warheads separated from each other and from the real warhead and following essentially the same trajectory as the real warhead, which provide the same radar image as the real warhead, practically make it impossible to identify and intercept the real warhead by overwhelming any star war defense and strategy.

4 Claims, 2 Drawing Sheets

\section{U.S. Patent May 16, 1989}

Sheet 1 of 2

$4,829,905$

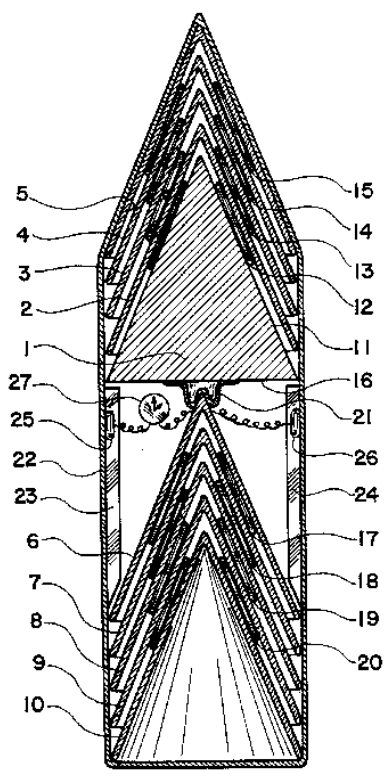

Fig. I

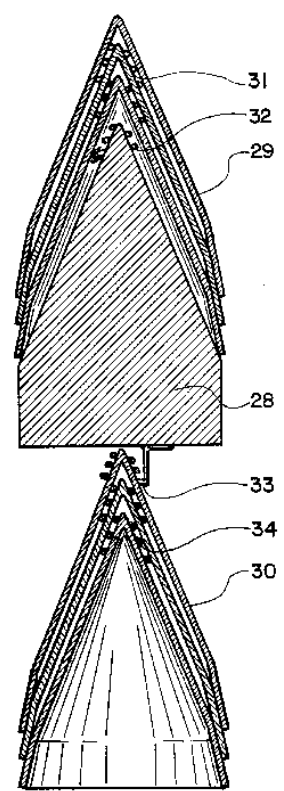

Fig. 2 


\section{We had already thought of it}

- Inflatable decoy for the Minuteman III, complete with radar

- X-band radar looks at external dimensions and shape only
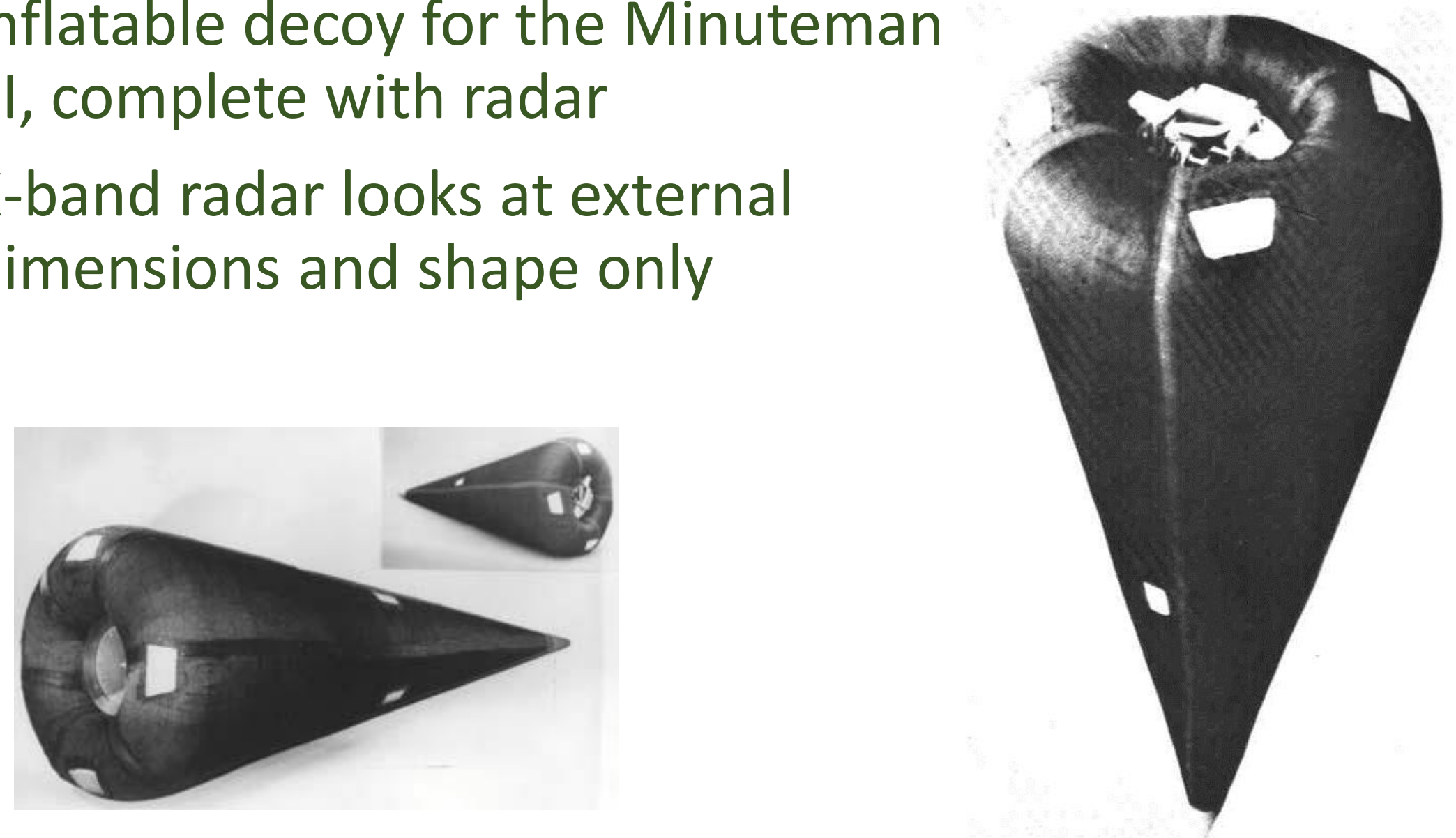


\section{Terminal (is a good term)}

- Terminal

Very short duration, re-entry, matter of seconds

Target may have velocities in excess of Mach 12 or

$13,000 \mathrm{foot} / \mathrm{sec}$

- Currently, we have very limited midcourse defense and extremely limited boost and terminal phase defense 


\section{Does all this work?}

- Let's say Uncle Kim decides to attack with an ICBM, what happens next? Can we defend America?

- Well, to be truthful, no one really knows.

- The U.S. has total of 36 interceptors currently deployed-four at Vandenberg Air Force Base in California, and 32 at Fort Greely in Alaska. Eight more GMD with EKV kinetic kill vehicles coming very soon.

- Of the 18 GMD test from 1999 to 2017 there may be 10 "hits" and this is with the "scripted" test. 


\section{How we will respond}

- The plan is to fire four interceptors at EACH incoming warhead to improve the chances of success to $97 \%$, theoretically.

- If you account for random failures plus common mode difficulties such as operating at night, during a period of unplanned maintenance at one or more key radars, or during a period of intense solar activity or bad weather, the effectiveness will drop drastically.

- There are numerous other shortfalls such as limited field of view in the SBX radar that also detract from the effectiveness of the entire system. 


\section{What is Uncle Kim gonna launch}

- The older North Korean missile the Hwasong-13 is similar to early U.S. ICBMs like the Minuteman 1, with the re-entry vehicle and $O N E$ warhead mounted directly to the top of the missile
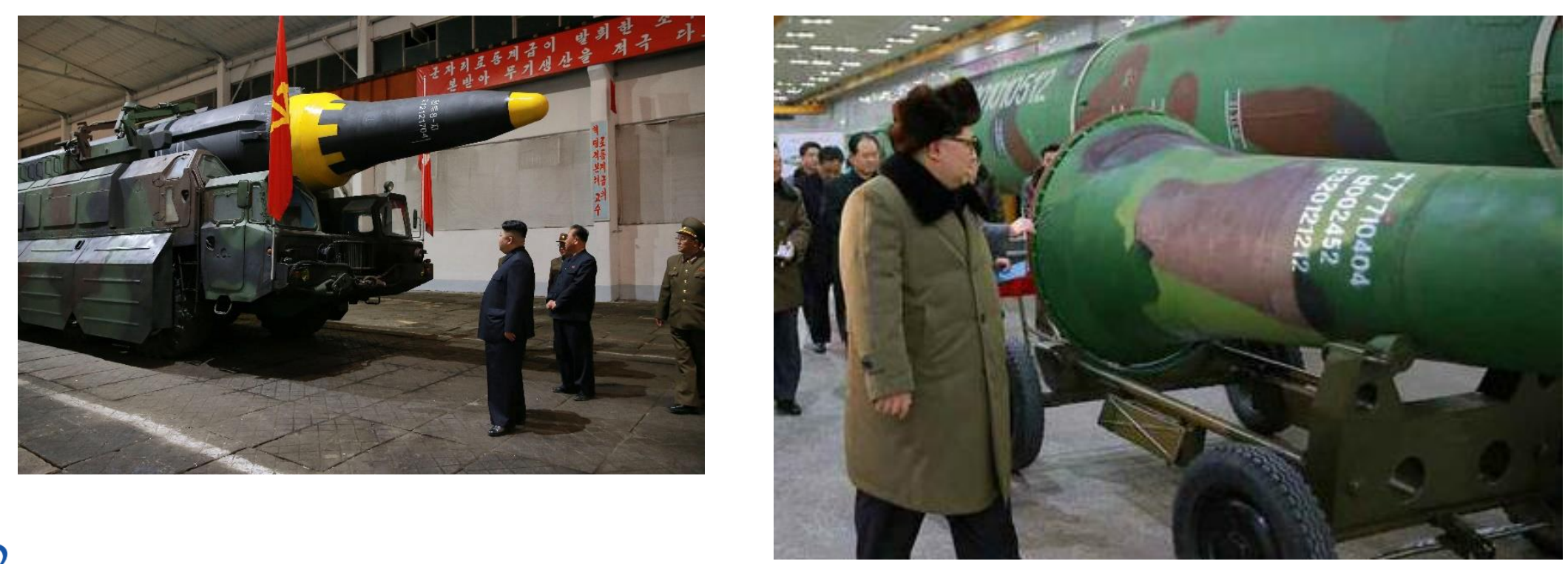


\section{What is Uncle Kim gonna launch}

- The new North Korean missile the Hwasong-14 has a heat shield covering multiple warheads, decoys (a major problem), chaff and other countermeasures. This adds exponential complexity to defense.
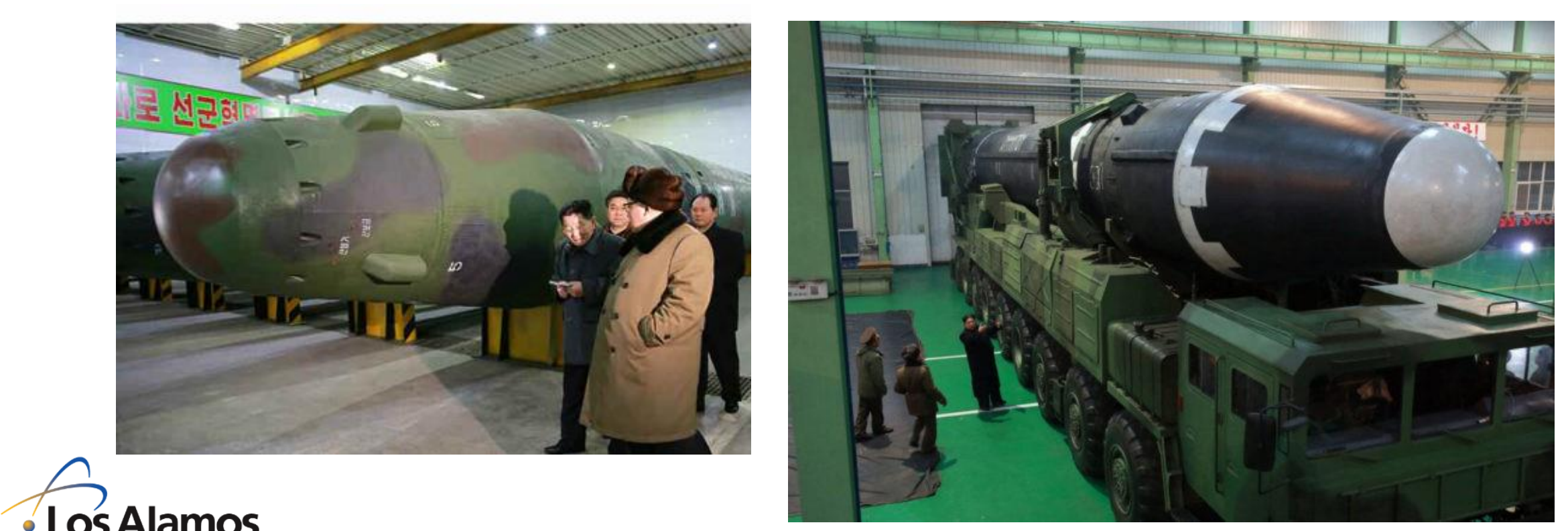


\section{So}

- In reality, what would an engagement look like?

- With NK in their infancy of missile development, the U.S. still diligently working on a problem that indescribably difficult

- The is how I see the conflict play out........

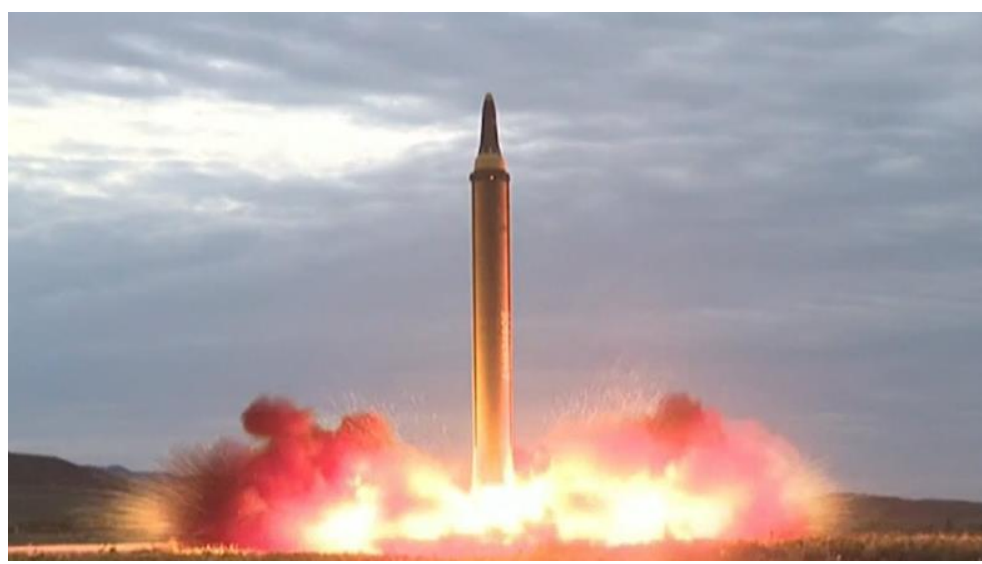


NK vs.US

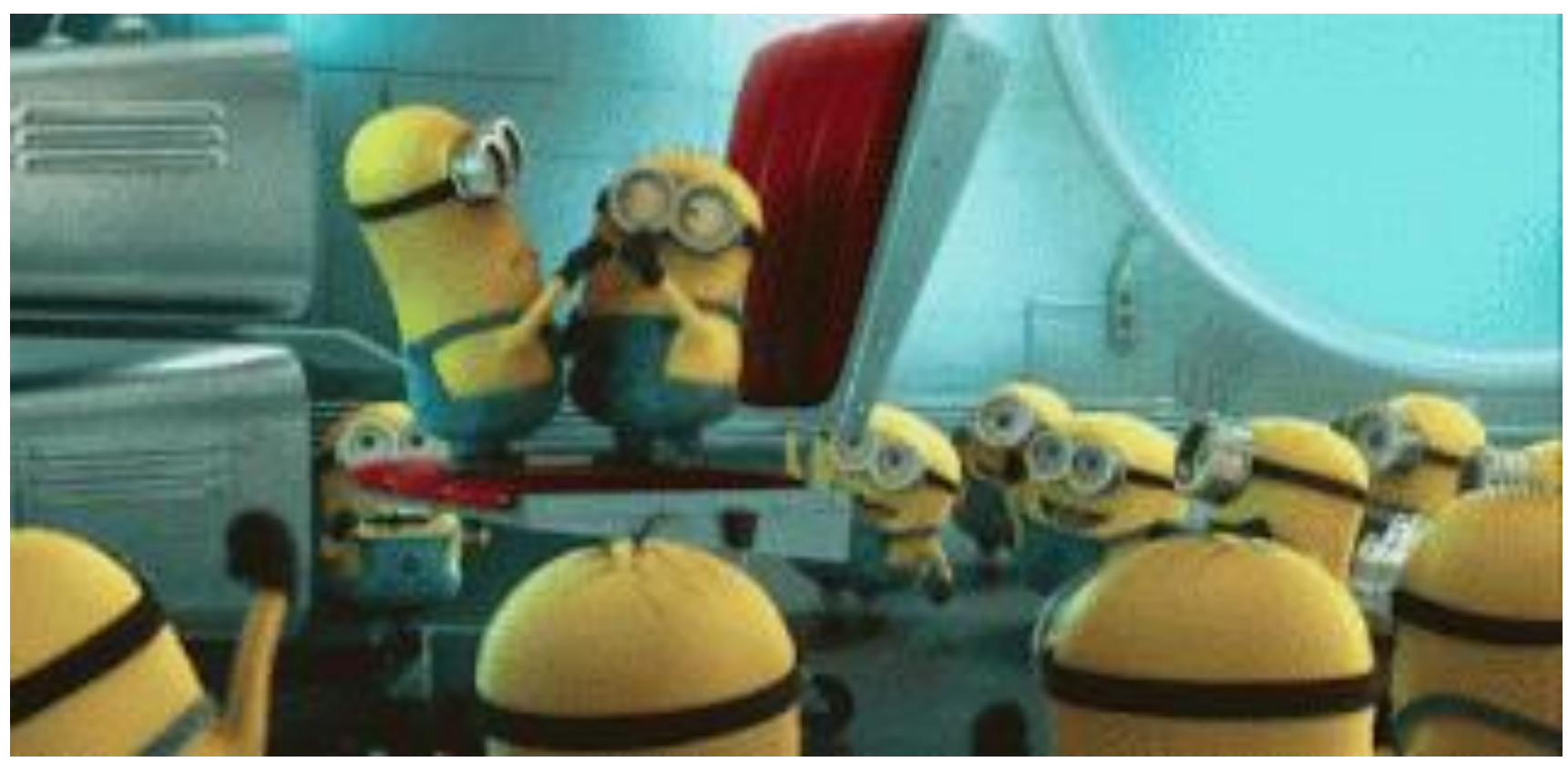

Sos Alamos EST. 194 


\section{Ballistic Missile Defense}

- This is a task almost as difficult as controlled thermonuclear fusion.

- Even with modern computers, speed of data processing is still limited.

- By far the biggest obstacle in a successful ABM system is the ease of adding countermeasures.

- Even the most sophisticated and accurate defense system can often be rendered impotent with the simple and cheap countermeasures. 


\section{Ballistic Missile Defense}

- If you ever get a chance to work on ballistic missile defense, DO IT.

- You will never be more challenged in your career.

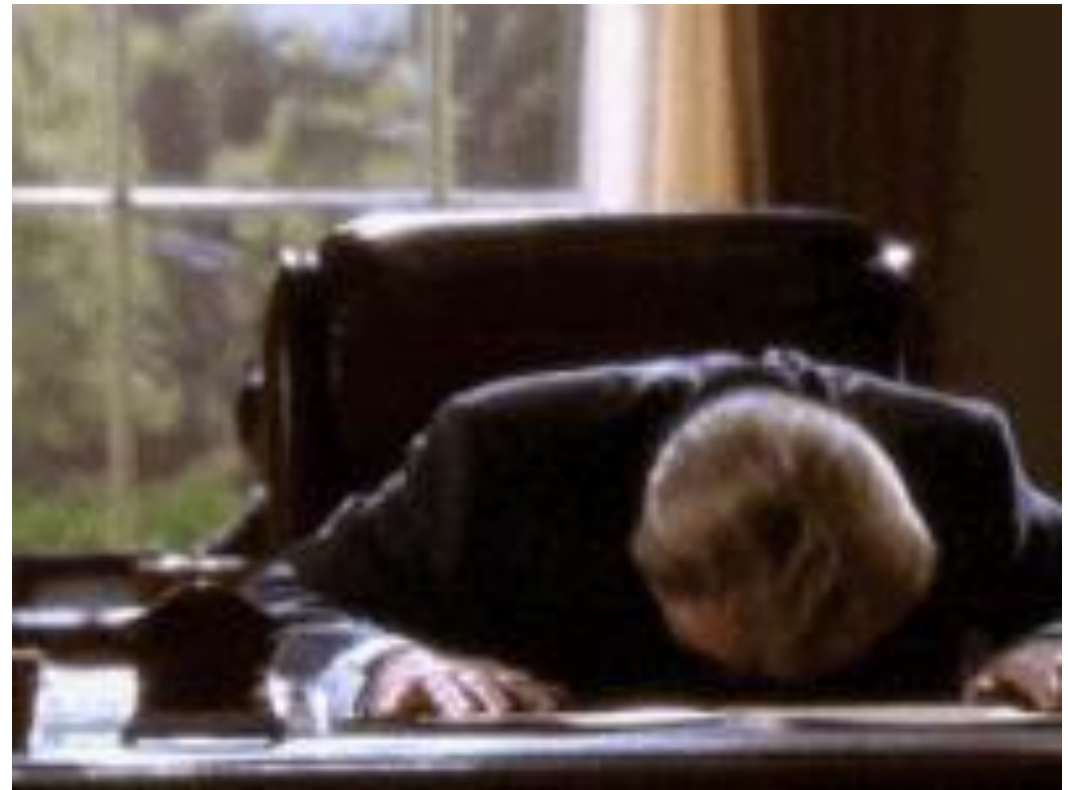

